\begin{tabular}{ll}
\hline$\Omega$ & Q \\
Lindsay Zurba & linds@icon.co.za \\
& in \\
Spirometry Training Services Africa CC, Durban, South Africa. & van-der-linden-52326037
\end{tabular}

\title{
Spirometry: coming of age in Africa
}

Africa is a continent of challenges. It is also a continent of positive change. It isn't easy getting up at $4 \mathrm{am}$ to get ready for a day helping hundreds in a rural clinic. It isn't easy being the decision maker allocating resources to make key work possible, given the complex demands on government and corporate finances. My African experience tells me that there are yet many rivers to cross, but we are making progress together. For me, there is no job that is more rewarding than helping so many to achieve a higher quality of health, longer lives and greater confidence: seeing a child encumbered by debilitating asthma freed and living a healthy life, or a group of healthcare professionals inspired and using spirometry for the first time, making considerable change to the care they deliver. It takes a network of teams to make it happen. My professional life parallels the growth of spirometry and respiratory health in Africa, and in sharing, I want to give you an insight into this important part of African diagnostic healthcare.

A few words from some key respiratory health innovators have resonated with me:

When Tom Petty, MD, speaks we had better all listen ... because we are still unable to cure many lung diseases, we had better get busy preventing lung disease.

Richard Casaburi [1]
Petty [1] picks his number one weapon in our efforts to prevent and treat respiratory disease as the "lowly spirometer". As far back as 1997, he called for widespread distribution of spirometers to measure airflow and air volume for a variety of clinical indications.

When Pettr [2] published these words in 1997, I was not aware of his research, nor did I know about John Hutchinson, the man who correctly predicted that premature morbidity and mortality could be identified by a reduced vital capacity 1846, but I wish I had known them. Two decades later these insights and wisdom on spirometry are as valid and meaningful as they were then, and never more so than in Africa today.

\section{Why it matters}

Sub-Saharan Africa faces some difficult health challenges. With $11 \%$ of the world's population, it carries $24 \%$ of the global disease burden. With $<1 \%$ of global expenditure, it has only $3 \%$ of the world's health workers [3]. Africa accounts for almost half the world's child deaths under the age of 5 years, has the highest maternal mortality rate, and bears a heavy toll from HIV/AIDS, tuberculosis and malaria. Noncommunicable diseases (NCDs) are quickly on the rise, growing
Cite as: Zurba L. Spirometry: coming of age in Africa. Breathe 2016; 12: 205-208. 
by $300-400 \%$ in the last two decades in some countries [3].

Africa carries a disproportionately high burden of respiratory morbidity and mortality relative to the population size. The burden of infectious diseases as well as NCDs, such as chronic obstructive pulmonary disease (COPD) or asthma, is high in Africa [3]. Infectious diseases such as pneumonia, tuberculosis or HIV-associated respiratory illness are amongst the commonest acute illnesses in African populations [3]. Asthma is the commonest NCD in African children and some of the highest COPD prevalence rates reported globally occur in African adults [4].

In an effort to ascertain the known burden of COPD in Africa, Stephen B. Gordon and $\mathrm{CO}^{-}$ workers [5] screened 132 articles yielding 22 relevant articles, of which only six used spirometry-based data. A total of 106 physicians in 34 countries were contacted, and only 23 reported satisfactory use and availability of spirometry.

The need to make spirometry available, coinciding with proper interpretation of results in Africa is especially important. Approximately $90 \%$ of COPD deaths are in low- and middle-income countries [6]. There continues to be lack of dedicated respiratory medicine infrastructures and expertise in these low-income African countries to perform longitudinal and long-term comprehensive level lung health assessments. With NCDs becoming the predominant focus in healthcare, spirometry is essential for the diagnosis, monitoring and treatment of COPD, and is useful in the diagnosis and treatment of asthma.

\section{While the environment may appear challenging, there are great things happening in Africa}

Life expectancy has increased [7]. Advances made in the treatment of HIV/AIDS and tuberculosis have resulted in a dramatic improvement in health outcomes in South Africa, including increased life expectancy, and reduced infant and child mortality rates [7].

\section{Getting started}

"To become old and wise you had to have been young and stupid first". My story starts in November 1996. As an intensive care sister with little career experience outside hospital routines, I lived in a world of bright lights, beeping monitors and fastpaced emergency action. Suddenly, I was on a career path I never could have dreamt for myself. With just $2 \mathrm{~h}$ of informal handover of equipment, I became responsible for a full lung function testing laboratory: less emergency action but higher stress levels. I thought I could wing it, teach myself in a jiffy. Sometimes it is better launching oneself in the unknown without facing a mountain of daunting information, otherwise one may never take the risks. 20 years later, I am humbled by how much there is still to learn about lung function testing and spirometry.

The manual for the equipment became my best friend. I needed those guides the way a young girl needs a friend to talk things through. My "best friend" and I took an inordinate length of time to bond. Sections written in technical English seemed a new foreign language. Looking back on it now, it was simple, but for me then, the words on the pages seemed like technical wizardry.

The practical applications of the manoeuvres were mastered quickly. Now and again, a patient would, of his own accord, blow three perfectly acceptable, superimposed manoeuvres. I didn't understand the implication of this on the numbers but I intuitively knew that the test was good. I built on this sixth sense in recording accurate lung function, and got nifty at coaxing acceptable and repeatable spirograms from patients.

\section{The harder you work, the luckier you get}

The years that followed melted into each other in a memory now of unprecedented hard work and unparalleled learning. 18-h days consisted of lung function testing, research, practice administration and managing ringing phones; fast food take-aways and a house that was not needed. The good news is that I was learning fast. I made mistakes, and had moments of feeling overwhelmed, perplexed and bewildered, but never found something that I could not do by thinking the situation through, reading my resources and carefully advancing.

\section{Breakthrough}

It was in 2000 that I heard about pulmonary technician on the other side of the city. I had never heard of such a qualification. I made contact leading to a visit where I was kindly assisted with answers to many questions. My new friend also gave me a blue and green covered book, The Manual of Pulmonary Function Testing by Gregg Ruppel, which replaced my equipment manual as my new companion. At last, certain parts of my daily work were starting to make sense.

A series of invitations to speak in various forums assisted my growth and learning. Speaking with confidence to groups was not easy for me. I was fearful at presenting on a subject in which I felt (and was) unqualified. Questions came that I could not answer and sent me scurrying back to my little blue and green book for answers that I was able to give later. 


\section{Passion ignited}

When choosing my career path, I wanted to be both a teacher and nurse. Nursing won but after teaching an afternoon session at the Durban University of Technology to occupational health students, I knew there was nothing I wanted more than to learn more about spirometry and pass on my knowledge.

I hired a colleague and taught her what I knew about lung function. We shared the lung function testing 50/50. In the months following, I made use of every free moment available writing my first spirometry training course. I used my little blue book, my practical experience and a few articles I had picked up at medical meetings for referencing.

When my course was ready, I started teaching at the Technical University. We started with one 4-day course every 3 months. This soon led to onsite courses in workplaces and clinics, conducting spirometry testing around South Africa. My own genuine learning accompanied my teaching. Challenged with questions on anything and everything related to spirometry, I made it my business to find the answers from many sources. During this time, I enjoyed the addition to my life of my three beautiful daughters.

\section{Barriers and borders}

Barriers to learning reduced as access to the Internet became available. E-mail made communication easier and I started receiving regular e-mails with spirometry-related questions. I became more comfortable in the classroom, more able to access learning materials, less stressed about how much I did not know and more confident at presenting each section with understanding.

Around 2004, I took part on the spirometry committee writing the South African National Standard for the generation of acceptable and repeatable spirometry (SANS 451), published in 2008, and the South African Unit Standard 252125 forming the sectoral training basis. Throughout, I learnt from colleagues and other interested parties. Another highlight was attending the European Respiratory Society (ERS) School Course on Spirometry Training held in Amsterdam, the Netherlands, in 2007. Excitingly, I found myself in an auditorium of professionals who recognised spirometry as a uniquely valuable tool in working with patients and were at the cutting edge of spirometry. I had been presenting spirometry for 7 years and this was the first formal training I had received. I drank in every word. A lot I didn't understand still, but I was able to sit afterwards, study further and as time passed, lightbulb moments kept my professional life bright.

\section{Moving forwards with confidence}

By 2006, I had started training internationally, and some time later, was delighted to discover the availability of a diploma and later a degree module in spirometry. Further studies included smoking cessation, asthma and COPD. Making friends with the people who taught and examined me, and soon becoming colleagues, was a key life experience.

\section{Pan African Thoracic Society Methods in Epidemiologic, Clinical and Operations Research}

In 2011, support increased through an introduction to the Pan African Thoracic Society (PATS) Methods in Epidemiologic, Clinical and Operations Research (MECOR) faculty - thank you, Monica Fletcher (Education for Health, Warwick, UK). Likeminded professionals came together for the vision of African spirometry. Using the opportunity of the gathering of respiratory specialists from across Africa, spirometry training has been offered as additionally to PATS MECOR attendees every year since 2011. Training opportunities have additionally been extended to local healthcare professionals through PATS MECOR in Kenya over the past 5 years in the form of free World Spirometry Day, and Healthy Lungs for Life workshops and community events.

Another highlight was the World Spirometry Day 2012 entry to Guinness World Records by recording the highest number of spirometry tests in 1 day under one roof using 60 spirometrists from all over Africa. 2800 tests were conducted over 4 days.

The ERS Spirometry Driving Licence was introduced to Africa in 2013. 4 years later, $>100$ respiratory specialists from 15 African countries have had the opportunity to undergo this globally accredited certification. By 2015, we have been able to release five new spirometry trainers located in Kenya, Nigeria, Malawi and South Africa (figure 1). One of our Nigerian trainees has since relocated to Fiji, allowing people of that emerging South Pacific island country availability to the best in world-class spirometry knowledge.

\section{Unique challenges spirometry in Africa}

Africa is a fast-growing continent with a beautiful mosaic of people, but in the medical sphere, people suffer from a lack of essential resources 


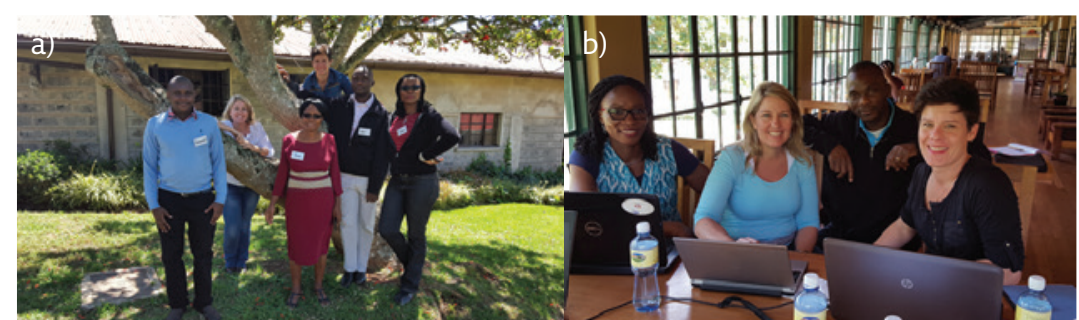

Figure 1 First training of African Spirometry trainers at PATS MECOR, Brackenhurst, Kenya, 2015. a) Left to right: ERS Spirometry Drivers Licence graduates and spirometry trainers in train ing Duncan Tumwa (Kenya), Lindsay Zurba, Rose Malamb (Malawi), Wendy van Wyk (South Africa), Ayodele Akinremi (Fiji) and Uju Ozoh (Nigeria). b) Left to right: Uju Ozoh, Lindsay Zurba, Ayodele Akinremi and Wendy van Wyk.

and appropriately trained staff to deal with health challenges. There is a daily struggle for access to the most simple of health care resources.

\section{Into the future}

With new vistas open daily, established and expanded old and new applications for clinical spirometry are at hand. Spirometry apps for mobile devices enable home monitoring.

We need to keep current initiatives focused on foundational spirometry training geared to uniquely African scenarios that will immediately strengthen skill systems for respiratory health screening, monitoring and management. Future training initiatives will be improved through the development of a blended approach to training which combines distance learning, e-learning and face-to-face teaching. Post-course support will be as important as resources allow.

Following the successful PATS spirometry course held at the PATS conference in April 2016, we are seeing the start of a new PATS spirometry training initiative. This would be a PATS initiative that envisages up-skilling African health professionals in spirometry and capacity development so as to enable earlier detection of lung disease and effective monitoring of interventions.

My personal goal remains to drive spirometry in Africa so that the words of PETTY [1] describing the use of spirometry "as commonplace as testing for blood pressure and cholesterol" come to pass.

If you want to walkfast, walk alone; if you want to walkfar, walk together!

African proverb

If you are a health professional concerned with the health of people in Africa, please consider adding your donation towards mine and Tom Petty's vision for the widespread distribution of spirometry using this link: www.breatheafrica.org/themes

\section{Acknowledgements}

The author would like to acknowledge Michael van der Linden (Durban Lung Centre, Durban, South Africa), Karen Michell (Concept Safety Systems, Johannesburg, South Africa), Sonia Buist (Oregon Health and Science University, Portland, OR, USA), Monica Fletcher, Christine Loveridge (both Education for Health, Warwick, UK).

Reggie Stiglingh, Agatha Pretorius (both Occupational Care South Africa, Johannesburg, South Africa), Stephen B. Gordon (Malawi Liverpool Wellcome Trust, Malawi), Kevin Mortimer (Liverpool School of Tropical Medicine, Liverpool, UK) and Jane Ardrey (BREATHE, Liverpool School of Tropical Medicine, Liverpool, UK) for their supportive role in my development and journey.

Conflict of interest

None declared.

\section{References}

1. Petty TL. Spirometry comes of age. RT 1997; 103: 51-54

2. Petty TL. Spirometry for All. RT 1997; 10: 18.

3. IFC World Bank. The Business of Health in Africa: Partnering with the Private Sector to Improve Lives. Washington, World Bank, 2007.

4. Zar HJ, Aluoch J. Advancing Lung Health in Africa, a global imperative. The Pan African Thoracic Society (PATS), 2016.

5. Mehrotra A, Oluwole AM, Gordon SB. The burden of COPD in Africa: a literature review and prospective survey of the availability of spirometry for COPD diagnosis in Africa. Trop Med Int Health 2009; 14: 840-848.

6. Buist AS, McBurnie MA, Vollmer WM, et al. International variation in the prevalence of COPD (The BOLD Study): a population based prevalence study. Lancet 2007; 370: 741-750.

7. South African Government News Agency. Great improvements in access to healthcare services. www.sanews.gov. $\mathrm{za} /$ south-africa/great-improvements-access-healthcareservices-0 Date last accessed: June 15, 2016. 